\title{
A Ramb é Incluída no ISI
}

No dia 8 de maio de 2007, I I meses após ter solicitado a sua inscrição, a Ramb obteve a inclusão no Science Citation Index Expanded(SCIE). Ainscrição no Web ofScience, que compreende trêsáreas (Science Citation Index Expanded, Social Citation Indexe Arts \& Humanities Citation Index), éum desejo de todo periódico, não só pelo certificado de qualidade, mas pela inclusão em um dos mais importantes índices bibliométricos do conhecimento: o fator de impacto ISI (Institute for Scientific Information). Além de divulgar o final feliz desta história, este editorial detalha o processo de obtenção para colaborar com outros periódicos responsáveis pela divulgação da pesquisa científica no Brasil.

A proposta enviada para o Programa de Desenvolvimento Editorial da Thomson Scientific, na Filadélfia, Estados Unidos, incluía, conforme as normas, a solicitação formal, os últimos três números da Ramb e uma carta explicativa do significado da revista para a ciência brasileira. A elaboração desta carta foi um capítulo à parte para este editor, que refletiu por muito tempo sobre seu conteúdo. A eventual necessidade de tornar a Ramb uma publicação em língua inglesa, a exemplo de outros periódicos nacionais e internacionais, jáfoi objeto de um editorial no ano 2000'. O assunto freqüentementevemà tona nas reuniões do Conselho Editorial, mas o "descolamento" da obrigatoriedade do inglês da aprovação no ISI ganhou adeptos: uma pesquisa brasileira observou que publicar em inglês não éuma garantia de fator de impacto elevado ${ }^{2}$.

No conteúdo da carta, procurei demonstrar o crescimento da produção científica brasileira em qualidade e quantidade, citando dados e gráficos obtidos na Fapesp, CNPq e Scielo. Uma análise dos periódicos latino-americanos incluídos no /SI-Web ofSciencepermitiu a comparação com as características e a personalidade da Ramb e de seus leitores, já indicadas previamente ${ }^{3-4}$. O foco central do documento foi descrever as lacunas profundas e importantes na divulgação científica para um público em franco crescimento numérico e econômico. Paralelamente, enviei o histórico da Ramb, publicada desde a década de 1950 sem interrupções, as indexações nas principais bases de dados nacionais e internacionais (Medline, Scielo, Lilacs, por exemplo) e a produção científica do Conselho Editorial. Além disso, salientei que o intercâmbio de informações e a colaboração científica entre as comunidades latino-americanas devem ser estimulados e registrados por citações detectadas e aprimoradas por índices bibliométricos.

A Ramb é muito grata aos esforços de todos os editores, revisores, autores, leitores e à diretoria da $\mathrm{AMB}$ que, desde a sua criação, em 1958, contribuíram para esta conquista.

Bruno Caramell

EDITOR DA RAMB

I. A revista que queremos ou da qual precisamos? Rev. Assoc. Med. Bras. 2000, vol. 46, $\mathrm{n}^{\circ} 4$

2. Rocha e Silva, M. Publishing science in developing countries: the new players in the business. Clinics. 2006, vol. 61, no. 5, pp. 375-380.

3. Caramelli, Bruno. RAMB: bimensal, Qualis A Nacional e Qualis C Internacional. Rev. Assoc. Med. Bras., Fev 2005, vol.5I, n I, p.2-2. 4. Caramelli, Bruno. O registro público obrigatório de ensaios clínicos. Rev. Assoc. Med. Bras., Dez 2005, vol.5I, nº 6, p.30l-30l 